\title{
Recommendation systems and convergence of online reviews: The type of product network matters!
}

\author{
David Robert Stöckli *, Hamid Khobzi \\ Institute of Information Systems, University of Bern, 3012 Bern, Switzerland
}

\section{A R T I C L E I N F O}

\section{Keywords:}

Recommendation systems

Product recommendation networks

Word of mouth

Electronic commerce

Econometric analysis

Opinion convergence

\begin{abstract}
A B S T R A C T
This paper examines the association between product networks generated by recommendation systems and the product ratings' convergence of products. It further investigates how different types of product networks are associated with a customers' perception of quality between product pairs in a product network. Additionally, this study examines whether the type of product networks are associated with the convergence of expressed sentiments for products in a product network differently. Data is collected from a major Swiss e-commerce platform and analyzed via various econometrics models. The results suggest that a network connection between two products via a "substitute" recommender system leads to a convergence of the two products' ratings. In contrast, a connection via a "complementary" recommender system leads to the product ratings' divergence. Additionally, consistent findings are shown to be present when examining the association between the network connection and product sentiment convergence. The findings contribute to WOM and recommendation systems literature and provide interesting implications of the practice.
\end{abstract}

\section{Introduction}

Electronic commerce (e-commerce) remains a rapidly growing industry. In 2019, retail e-commerce sales worldwide amounted to 3.53 trillion U.S. dollars. With annual growth rates of $17.6 \%$ per year since 2014, e-commerce revenues are estimated to be around 6.54 trillion U.S. dollars in 2022 [1]. Nevertheless, extraordinary events such as COVID19 , as a global crisis, may make such forecasts questionable. In April 2020 alone, the global e-commerce has experienced a substantial growth in many retail sectors (e.g., $209 \%$ in general retail) compared to all global online retailers' transactions in the same period in 2019, as instore activities faced wide-range restrictions due to the COVID-19 pandemic [2]. This sheds more light on the ever-important role of ecommerce for business and society, especially when the traditional physical stores are not available or accessible.

The Internet has given word-of-mouth (WOM) a new significance by allowing individuals to express their opinions and thoughts to a global audience, and so, it is an essential aspect of e-commerce [3]. Customers can simply express their opinion in an electronic form of WOM, and others can adopt such opinions in their decision making regarding purchasing products. In this regard, opinion convergence/divergence, as a social phenomenon, has drawn the attention of the stakeholders in e- commerce in recent years. In general, opinion convergence refers to the situation in which customers' opinions coincide with regard to a product. In contrast, opinion divergence is the situation in which consumers have varying opinions about the product and could be extremely opposite [4]. Whether it is the convergence of ratings, reviews, or comments for a focal product, or the convergence of ratings, reviews, or comments between a pair of connected products in a product network in an online store [5], research has shown promising insights on the importance and utility of convergence/divergence of opinions for business. As suggested by the literature, with having a potential role in consumers' decision making [4], deriving or diminishing sales [5], and in helpfulness and informativeness of reviews on an online platform $[6,7]$, yet there is only a handful of research studies looking at the phenomenon of convergence/divergence of opinions in e-commerce.

The movement from traditional retail stores to online shops has allowed companies to provide customers with more options that are more customized and tailored to their needs. One major drawback is the increasing amount of information a customer must process to find their item of choice. A solution to this information overload problem is the use of recommender systems, which assist consumers in their purchasing decision. Recommender systems not only facilitate a better purchase experience, but they have additionally been shown to increase sales [8].

\footnotetext{
* Corresponding author.

E-mail addresses: robertstoeckli@outlook.com (D.R. Stöckli), hamid.khobzi@iwi.unibe.ch (H. Khobzi).
} 
Although there are only a handful of widely used recommender algorithms, all online stores apply them in different ways and often adapt them to their needs [9]. A majority of e-commerce stores frequently use multiple recommender systems to support their customers in their purchasing decision. Amazon, for instance, extended their initial recommender list to include two additional ones (i.e., 'Frequently bought together' and 'Customers who viewed this item also viewed'). Moreover, each recommender system is trained differently to recommend different groups of products. Each recommender's type or goal is a determinant of the training procedure and the features it takes as input attributes. Therefore, the nature of a product network (i.e., the network of products that are connected with hyperlinks due to recommendations) for each type of recommender system differs, and this differentiation is shown to be a potential determining factor for WOM, such as online reviews in terms of product ratings [5], and, possibly, for the sales quantity of recommended products [10].

While previous literature focused more on the global network level, there are a handful of research studies that investigated product networks at the dyadic level in recommendation systems and contributed to the emerging research stream of product networks [5,8,10-14]. Nevertheless, prior research has paid little attention to the fact that products may be connected via different network types at a dyadic level, and yet, the plausible outcomes of different types of product recommendation networks remain unclear $[10,11]$. As an example, the research by Kumar and Hosanagar [10], suggests that the recommended products could be tied to a focal product in a network by a "substitute" or "complimentary" type of connection. Nevertheless, they exclusively focused on "substitute products" and examined the value of recommending such products on product pages of an e-commerce website in terms of sales. In another research, Lin et al. [11] investigated the impact of characteristics of two different types of product networks (i.e., co-purchase and co-view networks) on the sales quantity of products. Moreover, Lin and Wang [5] have exclusively focused on the co-purchase product network and investigated its effect on customer product evaluation in terms of review ratings. However, according to prior research, it has remained unclear whether the difference between varying types of product networks can be associated with customers' reviews.

Additionally, in this context, the majority of the literature that examines the relationship between WOM and sales only focuses on the WOM metric as a simple one-dimensional 1-5 rating and ignores the textual reviews that frequently accompany an online review, particularly as a dependent variable (or predictand). Apart from the finding that customers read review texts during their purchase decision [15], Ghose and Ipeirotis [16] point out that numeric ratings might not fully capture the sentiments expressed in reviews. For this reason, a simple WOM rating does not necessarily reflect a product's true quality and may provide only a part of the information. Therefore, textual reviews are of equal importance and, as such, are an additional determinant of purchase decision making [17]. Hence, the importance of customer reviews' textual characteristics, such as the review sentiment between two products, is of importance to be studied. All in all, with a focus on a major Swiss e-commerce store, this paper draws on the spillover effects in product networks to investigate the plausible association between different types of product recommendation network that connects two products in a dyadic relationship and customers' reviews.

This research's contribution to the emerging literature on product networks and opinion convergence is threefold. First, it extends the existing knowledge on the spillover effect of online WOM in product networks by differentiating between the types of the network connection between two products. Findings show that a network connection between two products via a "substitute" recommender is associated with the convergence of the two products WOM ratings. In contrast, a connection via a "complementary" recommender is associated with WOM ratings' divergence. Therefore, the type of product network matters! Second, this study incorporates the numerical ratings and textual characteristics of reviews, which allows for the examination of sentiments expressed by customers. Findings show that a connection of "substitute" ("complementary") type is associated with the convergence (divergence) of the two products' overall review sentiments.

Last but not least, unlike the existing literature in the underlying context that has mostly relied on data from e-commerce stores such as Amazon.com or Tmall.com, this study adds to the conversation by presenting insights drawn from data of a different e-commerce store based in Switzerland. Besides contributing to the generalizability of the findings in the underlying literature, this study emphasizes the different characteristics of e-commerce stores regarding their recommendation systems. This study also provides valuable implications for practice as well, which are discussed later in the paper.

The rest of this paper is organized as follows. First, the research background is reviewed, and later the relevant hypotheses are derived. Next, the methodological approach is explained by presenting the data and empirical analysis. Afterward, the results are presented and followed by a discussion on findings, limitations, and a conclusion of the study.

\section{Research background}

\subsection{Recommendation systems}

A recommender system could aid or influence consumers by displaying products that might be of relevance to them. They have been shown to increase sales, particularly when it comes to e-commerce recommendations $[8,18]$. The necessity for recommender systems in ecommerce becomes apparent when we compare a physical bookstore with an online bookstore. In retail, one is limited by a scarcity of resources. Only a limited number of shelves are available for presenting books to the consumer, so one is forced to only show the popular bestsellers. Amazon, on the other hand, has no such limitation and can offer millions of books simultaneously. Due to the information overload problem, an e-commerce vendor cannot present all available items to the user as it would overwhelm and discourage the user from buying any product. This phenomenon, often called the long-tail phenomenon, forces an online vendor to recommend items to individual users to assure a similar purchase experience as in retail [19].

Not all recommender systems are created equal, and they can differ substantially depending on the applied algorithm or field of application. The literature mainly distinguishes between two kinds of recommender systems: content-based filtering and collaborative filtering. Although one could differentiate the recommender systems by additional dimensions, such as application field (Book, Music, Movie, and so on) or data mining technique (Clustering, $\mathrm{k}-\mathrm{NN}$, association rule, and so on) [20], a distinction between the two most commonly used filtering algorithms suffices as discussed below.

Content-based recommendations recommend items based on attributes that describe the items. For instance, in the context of movie recommendations, such attributes would be the genre, year, or director of the movie. When consumers rate their products, user profiles can be created, which describes the consumer's preference regarding the individual attributes of the items. Similar items can then be suggested by matching them to the preferences of the user. A major drawback of these systems is that they tend to recommend similar items, which makes the recommendations simple and predictable [19].

While content-based filtering recommends items based on the item's characteristics, a collaborative filtering system makes recommendations based on other users' opinions. Therefore, apart from content-based filtering, a community of users is needed to make accurate recommendations. Collaborative filtering algorithms can be further classified into two categories: user-based collaborative filtering, where items are recommended to a user based on how other similar users rated these items, and item-based collaborative filtering, where items are recommended to a user based on how this user rated similar items. Because it is not restricted to the type of items to be recommended, collaborative filtering 
can be applied to most businesses if a community exists that is of a certain scale [19]. When Amazon launched its item-based collaborative filtering algorithm in 1998 ('Customers who bought this item also bought'), the algorithm rapidly rose to popularity and is now widely used in e-commerce, travel, news, and advertising [9].

\subsection{Product networks}

A product network is defined as a network in which the nodes are the products, and the edges are the hyperlinks between products that are generated by recommendation engines in most e-commerce platforms $[10,12,13]$. Modern studies on recommender systems focus on the network structure of product networks and the economic impact they have for the vendor. The literature on product networks is an emerging research stream [10,13]. The associations and relationships between products are now more visible due to the noticeable hyperlink connections of modern e-commerce recommender systems [8,13]. Moreover, the extended network-leveled analysis for recommender systems is said to be further effective and efficient for personalized services by finding the deep relation between products [21].

Oestreicher-Singer and Sundararajan [14] examined the impact of a product's position in such a hyperlinked network by applying a variant of Google's PageRank measure of centrality. By observing the copurchase (i.e., products that are bought together) recommendation networks of products in over 200 categories on Amazon.com, they showed that the network centrality of products in a category influenced a category's demand and revenue distribution. The more a category's products were influenced by the recommendation network, the flatter the distribution curve was. Additionally, Oestreicher-Singer and Sundararajan [8] studied the explicit visibility of product networks and the impact on demand spillovers over their constituent items and suggested that more centrally located products showed an increased demand. With a focus on the Amazon.com product network, Carmi et al. [13] investigated the depth of diffusion of exogenous demand shocks and showed a relatively shallow but yet economically significant contagion of information.

Moreover, Lin and Wang [5] extended the product network literature by focusing on the dyadic level in a co-purchase relationship between two products. Instead of only focusing on the sales impact, they additionally incorporated WOM ratings as a key dependent variable for their analysis. Their research's major finding was that the connection between two products led to a convergence of the two WOM ratings. They separately showed that the convergence of the two WOM ratings is associated with an increase in the total sales quantity of the two products. Huang et al. [12] conducted a similar analysis to see the impact of one type of product network and its attributes on product demand as well as the semantic similarity of product's reviews and product description. They showed that the more similar product reviews and products' descriptions are in a product network from a semantic perspective, the likelihood of having a higher demand for a focal product's demand.

Beside co-purchase (also referred to as complementary) product network, very few studies have focused on other types of product networks. These product networks are namely co-view (i.e., product pairs that if a customer views/likes the first she has also viewed/liked the second one [11]), substitute (i.e., product pairs that one of which could be bought in lieu of the other [10]), and similarity (i.e., product pairs that have similar attributes [12]) product networks. Lin et al. [11] suggested that the characteristics of a co-purchase product network are likely to influence product demand, while characteristics of a co-view product network do not exhibit such an influence. Kumar and Hosanagar [10] showed that the recommendation link between two products in a substitute product network could influence page views and sales. Huang et al. [12] showed that when two connected products in a similarity product network coincide in terms of having similar reviews and product descriptions, there is likely to be a negative spillover effect on product demand.

All the abovementioned studies exclusively focus on one type of product network, except for Lin et al. [11] that examined the effect of some characteristics of co-view and co-purchase product networks on product demand. Also, almost all of these studies concentrated on product demand, page view, and sales as a dependent variable, except for Lin and Wang [5], which focused on rating convergence. However, this paper is the first study that differentiates between multiple product network types and their plausible association with WOM convergence to the best of our knowledge.

\subsection{Word-of-mouth and online reviews}

The Internet has given WOM a new significance by allowing individuals to express their opinions and thoughts to a global audience [3]. Dellarocas [3] refers to WOM in an online environment as online feedback mechanisms that can include anything from recommender systems and online forums to search engine rankings. For this paper, WOM is more narrowly defined as online reviews (i.e., numerical ratings and textual reviews that reflect a consumer's opinion about a product).

WOM is an important source of information that helps individuals build a perception of a product's quality [22] and a trust-building instrument essential in e-markets where trust is much harder to gain than in traditional offline markets [3]. For a customer, without the possibility of experiencing and accessing a product physically, which is the case for e-commerce products, the only available option before making a purchase decision is to search for information. Particularly when it comes to purchasing an experience good, consumers attempt to perceive a product's quality by turning to various quality indicators, such as price, advertising, and online reviews [23].

Although the Internet provides the customer with most of the required information, the sheer amount of available information makes it difficult to obtain useful information when needed-a problem referred to as information overload. Although not all believe that the Internet is a major contributor to information overload, there is broad agreement that the increased availability of information has exacerbated the effect of the problem [24]. Value-added services can thereby help mitigate information overload by focusing on providing relevant information to the consumer [24]. Two of the most popular value-added services in e-commerce are WOM rating systems and recommender systems. Although different in their mechanics, both services qualify as recommendation strategies and have been shown to affect consumer decision making $[18,25]$.

The economic effects of WOM have been widely examined, and the literature shows a significant positive influence on sales for various consumer products particularly in the context of e-commerce $[15,18]$. For instance, Chevalier and Mayzlin [15] were able to show that an increase in volume or valence in WOM ratings led to higher book sales. While WOM's economic effects are a popular subject in the WOM literature, a more recent stream of research focuses on WOM as an outcome [5]. For instance, Lin and Heng [26] examined multiple WOM paradoxes and challenged conventional WOM wisdom in terms of sales. They concluded that better and a higher number of WOM ratings were not beneficial for all circumstances, due to the dampening effect of subsequent WOM ratings, which decreased and worsened as a result.

In this regard, a handful of studies in this stream have looked at factors that can lead to convergence or divergence of online reviews. As suggested by those studies, convergence/ divergence of opinions in ecommerce play a potential role in consumers' decision making [4], deriving or diminishing sales [5], and in helpfulness and informativeness of reviews on an online platform [6,7]. For instance, Lin and Wang [5] showed in their research that the existence of a connection between two products leads to a convergence of a connected product pair's ratings. Yet, only a handful of research studies look at the phenomenon of convergence/divergence of opinions in e-commerce. This research seeks to fill the existing gap in this stream by investigating the role of different 
types of product networks in the convergence/divergence of online reviews.

\subsection{Research hypotheses}

The potential relationship between recommender systems and WOM remains scarce in the literature [5]. Prior research has invariably investigated user and system recommendations' isolated effects, while they overlooked the potential interaction between these two [18]. Research has shown the importance of product networks and their outcomes for e-commerce [10-12,14]. This paper seeks to investigate the dyadic level in a product network, focusing more on the network connection between two products in a recommendation system. Research has also shown convergence of opinions (e.g., ratings, reviews, or comments) is associated with consumers' decision making [4], deriving or diminishing sales [5], and in helpfulness and informativeness of reviews on an online platform [6,7]. Thus, it is important to know the possible antecedents of opinion convergence.

In their paper, Lin and Wang [5] showed that a significant relationship exists between the network connection and the convergence of two products' WOM ratings. They argued that, due to the parallel presentation in a recommender system, the customer perceived the products as qualitatively similar, which led to a convergence in the two products' ratings. Additionally, the recommended product acted as a reference point, which caused the customer to leave a similar rating as the one it is connected to. Therefore, when two products were connected, the higher rating may have converged to the lower one, and the lower rating may have converged to the higher one, which in sum resulted in a convergence of the two products' ratings [5].

Such a phenomenon is based on the underlying theoretical explanation of the spillover effect of online WOM in product networks. In WOM communication, the spillover effect is the degree to which someone's beliefs change by the information presented in a message, particularly the beliefs about the attributes that are not directly communicated via the message [12,27]. Furthermore, the emerging literature on product networks has shown the diffusion of spillover (i.e., change of customers' beliefs) between connected products via a visible hyperlink in a product network [10,12,13]. Among the plausible outcomes of the spillover effect in product networks, prior research has shown the spillover of customers' demand between connected products in a product network $[10,13]$; or the spillover of the online WOM between connected products in a product network $[5,12]$.

The rating of a product has been widely recognized as a proxy for the underlying product's perceived quality, and as a means of WOM communication, it can help others in decision making [5,22]. This study postulates the plausible spillover of product ratings between connected products in a product network in a way that ratings are likely to converge when two products are linked. Accordingly, the following hypothesis is proposed:

H1. The network connection between the two products is likely to lead to the convergence of the two products' ratings.

While recommender systems and their network connections have been the subject of the majority of the recent literature, the type and characteristics of these network connections have generally been neglected. Frequently, authors investigated whether a product was connected via a recommender system of any kind and did not focus on the type or underlying mechanism of such a system, or exclusively focused on one type of product network [5,8,10,12].

A further distinction can be made by investigating the type of product network in a recommendation system based on features such as the algorithm or data mining technique used for the recommender system. Such factors are difficult to observe because there is generally no direct access to the underlying data and models used. Although a company can use the same recommender algorithm (e.g., item-based collaborative filtering) or the same mining technique (e.g., k-means) as another company, the two companies can have different outcomes. Depending on each recommender system's goal, the training procedure, and the features taken as input, attributes can fundamentally differ [19]. Moreover, customers' purchase decision making can be affected by being exposed to other customers' preferences (i.e., co-view) or their actual purchase behavior (i.e., co-purchase) differently [11]. In other words, being exposed to different sources of information because of the difference in the type of product network may influence customers in their purchase-related decision making and online behavior [11]. Thus, it is necessary to differentiate between varying product networks and determine their role in the online WOM communication spillover. Accordingly, the following hypothesis is proposed:

H2. The products' rating convergence differs significantly across different types of network connections.

Although the importance of capturing the sentiments expressed in product reviews is acknowledged, it is frequently neglected due to the reasons such as the difficulty of analyzing textual information [28]. In the context of product networks, the overall sentiments between two products may behave in a similar fashion as the WOM ratings. However, it is important to mention that the sentiment convergence offers information captured at the textual content level, and one cannot fully capture such information from WOM ratings [7]. Thus, examining sentiment convergence can bring about a further understanding of product networks' role in the convergence of the online reviews. Prior research suggests that sentiment convergence/divergence can strongly affect product sales [7]. On that account, it is beneficial to extend the existing knowledge on the antecedents of sentiment convergence, which is overlooked in the literature.

Presumably, drawing on the spillover effect of online WOM communication, it is expected that if the WOM rating of a pair of connected products converges due to the existence of the connection in the product network, the WOM polarity (i.e., overall review sentiments) is likely to converge as well. As mentioned earlier in this section, being exposed to different information sources because of the difference in the type of product network may be associated with customers' purchaserelated decision-making and online behavior [11]. Thus, this study posits that although a link between two products in a product network is likely to be associated with the convergence of their reviews' sentiment, it is also plausible that the type of product network is likely to lead to varying outcomes for the convergence of their reviews' sentiment. Accordingly, the following hypothesis is proposed:

H3. The products' review sentiment convergence differs significantly across different types of network connections.

\section{Methodology}

\subsection{Research context}

This study focuses on one of the largest online electronics stores in Switzerland. On the contrary, prior related research has mostly relied on data from e-commerce stores such as Amazon.com or Tmall.com. However, this study seeks to add to the conversation by focusing on a different e-commerce platform, which has a distinct way of recommending products compared to the abovementioned stores. Similar to other e-commerce platforms, each product is featured on a designated webpage where all major product details are displayed. The available product attributes are including product name, price, photos, configurations, description, and specifications. Further, one can observe the customers' average ratings and their reviews about the focal product.

It is important to differentiate between online platforms since each of them may have varying characteristics (e.g., website design), context, and target audience [4]. A major difference between the underlying Swiss e-commerce platform and the other e-commerce platforms is in its product recommendations, which is the main reason why it was selected 
for this research. The recommended products are displayed on a sidebar and visible without scrolling down the page. Additionally, the recommendations are limited to three products per recommender. The underlying e-commerce platform uses five different types of recommenders, namely "Often bought together," "Bestselling < name of product category $>$," "Current bestsellers," "Similar products," and "You might also like." Usually, two of these are shown simultaneously on the sidebar. Nevertheless, exceptions were observed where occasionally, only one or three types of recommenders were displayed. When and which types of recommenders are shown on a product page is not fully ascertainable. It is likely that depending on the popularity or category of the product, some recommender types are displayed more often than others are. The recommender type 'Similar products' was rarely shown during data collection and was therefore not included in the analysis. Additionally, during the data collection period, the interface of this ecommerce platform was changed. On 11.12.2019, the recommender type 'You might also like' was removed from the sidebar and placed further down in a list. As a result, the data for this type of recommender system could not be collected after this date due to the data collection procedure.

The recommendation algorithm that is employed by this e-commerce platform for each type of recommender system is not known to the public. "Often bought together" is comparable to recommender systems from other e-commerce platforms and probably uses some form of collaborative filtering algorithm or association rule to make its recommendations. It can be defined as a paired recommendation [29], where the recommended product is usually a complementary good, which is often bought together with the focal product. The recommended product is, therefore, often a product of another category. This type of recommender (or product network) is referred to as a "complementary" recommender hereafter.

'You might also like' additionally shares some similarities with other recommender systems, where similar products based on product characteristics are recommended to the customer. The recommended products are often variants of the same product or similar products of another brand and are, therefore, often products of the same category. This type of recommender system is comparable to the "substitute" recommender system observed by Kumar and Hosanagar [10]. Accordingly, this type of recommender (or product network) is referred to as a "substitute" recommender henceforth.

No underlying algorithm could be discerned for the other two recommender systems (i.e., "Bestselling $<$ name of product category $>$ " and "Current bestsellers"). Like traditional retail stores, they seem to show only products that are the most popular and the most purchased in the e-commerce platform and ignore other users' preferences for recommendations. These two recommenders are referred to as "bestselling" and "top-sellers" hereafter, respectively.

\subsection{Data description}

Data were collected from the top 100 mobile phones on the Swiss ecommerce platform on a daily basis at midnight through the months of November and December in 2019 for a period of 31 days. For each mobile phone, the data on all the recommended products were gathered as well. Therefore, the source product (i.e., the focal product) in the product network could only be a mobile phone, while the destination product (i.e., recommended product), in theory, was any product that was listed on the online store. In reality, $98 \%$ of the recommended products in the dataset were either other mobile phones or mobile phone accessories such as cases, screen protectors, sim-cards, and so on. Although a mobile phone can be classified as a typical search good, the technical complexity and variety make it difficult to perceive its quality prior to purchase. A mobile phone is an example of a high-involvement good, where a consumer is likely to spend a significant amount of time conducting information searches before purchasing the product. Therefore, value-added services, such as WOM rating and recommender systems, become increasingly important for the customer in his purchasing decision-making. Accordingly, the network connections were constructed between pairs of products via the recommendation relationships.

Since the top 100 list changed each day naturally, the observed products would additionally change daily. Therefore, the dataset is unbalanced. The data on product attributes were also collected, such as product name, price, category, customer ratings, and reviews. The entire dataset for all 31 days included 2,025,740 observations for 309,206 product pairs, which were constructed based on 7862 products. In our data, the average price across all products was 349 Swiss francs (St. dev. $=414.27$ ). Moreover, the average review volume and the average product rating across all products was $31(S t$. dev. $=42.83)$ and 4.092 (St. dev. $=1.39$ ), respectively. The majority of the product attributes proved to be highly skewed, particularly when it came to product ratings. In the collected data, the product ratings were mostly positive, where $79 \%$ of the ratings lay between a rating of 4 and 5 . Table 1 mentions the variables included in the empirical analysis, and Table 2 presents the descriptive statistics as well as the pairwise correlation matrix for all variables. Regarding product networks, the average daily network connection for complementary, substitute, best-selling, and top-seller product networks were 241.03 (St. dev. $=16.44$ ), 252 (St. dev. $=2.98), 149.07$ (St. dev. = 12.11), and 116.07 (St. dev. = 10.91), respectively.

The WOM polarity for each product was calculated to determine the sentiment convergence for the sentiment model. Due to Switzerland's multilingualism, the e-commerce platform reviews were first translated into a common language (i.e., English). Using Google's Cloud Translation API, all reviews were first translated into English reviews with their pre-trained neural machine translation [30]. For the natural language processing (NLP), the PatternAnalyzer algorithm from the free Python NLP library TextBlob was used [31], which was based on the Pattern library [32]. The PatternAnalyzer can conduct a polarity analysis, which is the determination of the writer's emotional attitude concerning the topic under discussion [33]. A text's polarity is determined by assigning scores for negative and positive polarities for each word in the lexicon. The PatternAnalyzer's polarity score ranges from -1 to 1 , where -1 represents strong negative sentiments while 1 represents strong positive sentiments. A polarity score of 0 suggests a neutral sentiment. Using the PatternAnalyzer, each review was assigned with a polarity score. By calculating the mean polarity score for a product, the WOM polarity for every product was established. Similar to the product

Table 1

Variables description.

\begin{tabular}{|c|c|}
\hline Variable & Description \\
\hline$\Delta p r$ & $\begin{array}{l}\text { Product ratings' convergence, which is the absolute difference } \\
\text { between average ratings of a pair of connected products in a product } \\
\text { network }\end{array}$ \\
\hline$\Delta p o l$ & $\begin{array}{l}\text { Sentiment convergence, which is the absolute difference between } \\
\text { overall review sentiments of a pair of connected products in a product } \\
\text { network }\end{array}$ \\
\hline connection & $\begin{array}{l}\text { Network connection, which is a dummy variable indicating whether a } \\
\text { pair of products are connected or not. }\end{array}$ \\
\hline$\Delta r v$ & $\begin{array}{l}\text { Review volume difference, which is the absolute difference between } \\
\text { the review volume of a pair of connected products in a product } \\
\text { network }\end{array}$ \\
\hline$\Delta l p$ & $\begin{array}{l}\text { The list price difference, which is the absolute difference between the } \\
\text { prices of a pair of connected products in a product network }\end{array}$ \\
\hline$\Delta i{ }_{-} d c$ & $\begin{array}{l}\text { In-degree centrality difference, which is the absolute difference } \\
\text { between the in-degree centrality of a pair of connected products in a } \\
\text { product network }\end{array}$ \\
\hline$\Delta o u t \_d c$ & $\begin{array}{l}\text { Out-degree centrality difference, which is the absolute difference } \\
\text { between the out-degree centrality of a pair of connected products in a } \\
\text { product network }\end{array}$ \\
\hline assortativity & $\begin{array}{l}\text { Same category connection, which is a dummy variable indicating } \\
\text { whether a pair of products are from the same category of products or } \\
\text { not. }\end{array}$ \\
\hline
\end{tabular}


Table 2

Descriptive statistics and pairwise correlations.

\begin{tabular}{|c|c|c|c|c|c|c|c|c|c|c|}
\hline & Mean & St. dev. & (1) & (2) & (3) & (4) & (5) & (6) & (7) & (8) \\
\hline (1) $\Delta p r$ & 1.06 & 1.41 & - & & & & & & & \\
\hline (2) $\Delta p o l$ & 0.18 & 0.16 & 0.45 & - & & & & & & \\
\hline (3) connection & 0.01 & 0.10 & -0.04 & -0.04 & - & & & & & \\
\hline (4) $\Delta r v$ & 36.96 & 43.76 & -0.04 & -0.05 & 0.00 & - & & & & \\
\hline (5) $\Delta l p$ & 403.58 & 367.58 & -0.02 & -0.02 & 0.00 & 0.01 & - & & & \\
\hline (6) $\Delta i n \_d c$ & 3.78 & 10.35 & -0.07 & -0.06 & 0.22 & 0.04 & 0.01 & - & & \\
\hline (7) $\Delta$ out_dc & 3.31 & 3.49 & -0.04 & 0.00 & 0.03 & 0.07 & 0.35 & 0.07 & - & \\
\hline (8) assortativity & 0.38 & 0.48 & -0.18 & -0.24 & 0.05 & -0.12 & -0.28 & 0.02 & -0.23 & - \\
\hline
\end{tabular}

ratings, the product polarities were mostly positive, where $73 \%$ of the polarity scores lay between 0.1 and 0.5 .

\subsection{Empirical analysis}

In this study's data, each source product could have a product network tie to any of the other 7861 destination products. All possible permutations of product pairs (network ties) are used as the unit of analysis. The model variables are, therefore, operationalized at the network tie-day level [5]. For all three hypotheses, the same empirical approach is used to conduct the analysis, which is a linear panel data model with fixed effects. To see whether the product network connection $\left(\right.$ connection $\left._{i t}\right)$ is associated with products' rating convergence $\left(\Delta p_{i t}\right)$, eq. 1 is modelled as a linear panel data model to test $\mathrm{H} 1$ and $\mathrm{H} 2$.

$$
\begin{aligned}
\ln \left(\Delta p r_{i t}\right) & =\beta_{1}{ }^{*} \text { connection }_{i t}+\beta_{2}{ }^{*} \ln \left(\Delta r v_{i t}\right)+\beta_{3}{ }^{*} \ln \left(\Delta l p_{i t}\right)+\beta_{4}{ }^{*} \ln \left(\Delta i n_{-} d c_{i t}\right) \\
& +\beta_{5}{ }^{*} \ln \left(\Delta \text { out }_{-} d c_{i t}\right)+\beta_{6}{ }^{*} \text { assortativity }_{i t}+T_{t}+a_{i}+\varepsilon_{i t}
\end{aligned}
$$

The subscript $i$ denotes each directed network tie, and the subscript $t$ denotes each time period (daily). The dependent variable for the first and second hypotheses is WOM convergence $\left(\Delta p r_{i t}\right)$, which is measured as the absolute value of the difference of review ratings between source and destination from network tie $i$ on day $t$. The dichotomous independent variable connection $n_{i t}$ indicates the existence of network tie $i$ from source to destination on day $\mathrm{t}$ and took on the value one for existence and zero for the non-existence of the connection. Due to the dyadic product-pair level analysis, information common across two products in a product pair and across different product pairs is used to construct the control variables, which are: review volume difference $\left(\Delta r v_{i t}\right)$, list price difference $\left(\Delta l p_{i t}\right)$, in-degree centrality difference $\left(\Delta i n_{-} d c_{i t}\right)$, out-degree centrality difference $\left(\Delta o u t_{-} d c_{i t}\right.$ ) and assortativity (assortativity ${ }_{i t}$ ). Assortativity indicates whether the source and the destination are from the same product category (assortativity $=1$ : same category; assortativity = 0 : otherwise). Additionally, the natural logarithm of all numerical variables is considered due to the skewness of their distribution.

For the sentiment convergence model, the dependent variable is replaced with the sentiment convergence $\left(\Delta p_{p o l}\right.$ ), which is measured as the absolute value of the difference of the mean polarity score (WOM polarity) between source and destination from network tie $i$ on day $t$. All other variables stay the same.

$$
\begin{aligned}
\ln \left(\Delta \text { pol }_{i t}\right) & =\beta_{1}{ }^{*} \text { connection }_{i t}+\beta_{2} * \ln \left(\Delta r v_{i t}\right)+\beta_{3}^{*} \ln \left(\Delta l p_{i t}\right)+\beta_{4} * \ln \left(\Delta i n_{-} d c_{i t}\right) \\
& +\beta_{5}{ }^{*} \ln \left(\Delta \text { out }_{-} d c_{i t}\right)+\beta_{6} * \text { assortativity }_{i t}+T_{t}+a_{i}+\varepsilon_{i t}
\end{aligned}
$$

\section{Results}

\subsection{Main findings}

The fixed-effects model is used as the preferred analysis to obtain consistent estimates despite the presence of the unobserved network-tiespecific heterogeneity, $a_{i}$ being correlated with the explanatory variables. The results for the first hypothesis are shown in Table 3. Since the $\Delta p r$ is measured as the absolute value of the difference in product
Table 3

Results of collective network connection on WOM convergence.

\begin{tabular}{ll}
\hline Variable & $\begin{array}{l}\text { Model (1) } \\
\text { (All connections) }\end{array}$ \\
\hline connection & -0.001 \\
& $(0.001)$ \\
$\Delta r v$ & $0.068^{* * *}$ \\
& $(0.001)$ \\
$\Delta l p$ & $-0.000^{* * *}$ \\
& $(0.000)$ \\
$\Delta i n \_d c$ & 0.000 \\
& $(0.000)$ \\
$\Delta o u t d c$ & $0.001^{* * *}$ \\
assortativity & $(0.000)$ \\
& $-0.130^{* * *}$ \\
Number of network ties & $(0.004)$ \\
Number of observations & $309^{\prime} 206$ \\
Number of days & $2^{\prime} 025^{\prime} 740$ \\
$R^{2}$ & 31 \\
\hline
\end{tabular}

Standard errors in parentheses. ${ }^{*} p<0.1 ;{ }^{*} p<<0.05 ;{ }^{* * *} p<0.01$.

ratings, the negative coefficients show that when two products are connected (connection $=1$ ), they have a smaller rating difference $(\Delta p r)$. In other words, their WOM (in terms of product ratings) may converge; but with a $p$-value of 0.337 , the result is not statistically significant. Therefore, the results fail to support $\mathrm{H} 1$ in that the network connection (considering aggregated data without considering the type of recommender system) leads to a WOM convergence between the two connected products.

\begin{tabular}{|c|c|c|c|c|}
\hline Variable & $\begin{array}{l}\text { Model (2A) } \\
\text { (complementary) }\end{array}$ & $\begin{array}{l}\text { Model (2B) } \\
\text { (best- } \\
\text { selling) }\end{array}$ & $\begin{array}{l}\text { Model } \\
(2 \mathrm{C}) \\
\text { (top-seller) }\end{array}$ & $\begin{array}{l}\text { Model (2D) } \\
\text { (substitute) }\end{array}$ \\
\hline connection & $\begin{array}{l}0.006^{* *} \\
(0.003)\end{array}$ & $\begin{array}{l}0.003 \\
(0.003)\end{array}$ & $\begin{array}{l}0.001 \\
(0.003)\end{array}$ & $\begin{array}{l}-0.019^{* * *} \\
(0.003)\end{array}$ \\
\hline$\Delta r v$ & $\begin{array}{l}0.068^{* * *} \\
(0.001)\end{array}$ & $\begin{array}{l}0.068^{* * *} \\
(0.001)\end{array}$ & $\begin{array}{l}0.068^{* * *} \\
(0.001)\end{array}$ & $\begin{array}{l}0.068^{* * *} \\
(0.001)\end{array}$ \\
\hline$\Delta l p$ & $\begin{array}{l}-0.001^{* * *} \\
(0.000)\end{array}$ & $\begin{array}{l}-0.001^{* * *} \\
(0.000)\end{array}$ & $\begin{array}{l}-0.001 * * * \\
(0.000)\end{array}$ & $\begin{array}{l}-0.001 * * * \\
(0.000)\end{array}$ \\
\hline$\Delta i{ }_{-} d c$ & $\begin{array}{l}0.000 \\
(0.000)\end{array}$ & $\begin{array}{l}0.000 \\
(0.000)\end{array}$ & $\begin{array}{l}0.000 \\
(0.000)\end{array}$ & $\begin{array}{l}0.000 \\
(0.000)\end{array}$ \\
\hline$\Delta o u t_{-} d c$ & $\begin{array}{l}0.001^{* * *} \\
(0.000)\end{array}$ & $\begin{array}{l}0.001^{* * *} \\
(0.000)\end{array}$ & $\begin{array}{l}0.001^{* * *} \\
(0.000)\end{array}$ & $\begin{array}{l}0.001^{* * *} \\
(0.000)\end{array}$ \\
\hline assortativity & $\begin{array}{l}-0.130^{* * *} \\
(0.004)\end{array}$ & $\begin{array}{l}-0.130^{* * *} \\
(0.004)\end{array}$ & $\begin{array}{l}-0.130 * * * \\
(0.004)\end{array}$ & $\begin{array}{l}-0.130 * * * \\
(0.004)\end{array}$ \\
\hline $\begin{array}{l}\text { Number of } \\
\text { connections }\end{array}$ & $7^{\prime} 776$ & $4^{\prime} 728$ & $3^{\prime} 603$ & $2^{\prime} 769$ \\
\hline $\begin{array}{l}\text { Number of } \\
\text { network ties }\end{array}$ & $309^{\prime} 206$ & $309^{\prime} 206$ & $309^{\prime} 206$ & $309^{\prime} 206$ \\
\hline $\begin{array}{l}\text { Number of } \\
\text { observations }\end{array}$ & $2^{\prime} 025^{\prime} 740$ & $2^{\prime} 025^{\prime} 740$ & $2^{\prime} 025^{\prime} 740$ & $2^{\prime} 025^{\prime} 740$ \\
\hline Number of days & 31 & 31 & 31 & 31 \\
\hline$R^{2}$ & 0.009 & 0.009 & 0.009 & 0.009 \\
\hline
\end{tabular}

The results for the second hypothesis are shown in Table 4. A

Table 4

Results of different network connections on WOM convergence.

Standard errors in parentheses. ${ }^{*} p<0.1,{ }^{* *} p<0.05,{ }^{* * *} p<0.01$. 
distinction is made between the different recommenders (product networks) in the data. The network connections of the two "complementary" and "substitute" recommenders are significantly associated with WOM convergence. Model (2A: complementary) shows a positive association with $\Delta p r$, which means that when two products are connected via network connection "complementary," they are likely to have a larger rating difference $(\Delta p r)$. In other words, their WOM (in terms of product ratings) may diverge. Model (2D: substitute) has negatively and significantly associated with $\Delta p r$, which means that the WOM (in terms of product ratings) may converge between the two products if they were connected within a "substitute" product network. For the other two network connections, "Bestselling Mobile phone" ("best-selling") and "Current bestsellers" ("top-seller"), no significant association with WOM rating convergence is found.

Instead of examining all models shown in Table 4, only the two significant network connections (i.e., "complementary" and "substitute") were chosen to analyze the third hypothesis. Model (3A) and (3D) in Table 5 show the association of a "complementary" connection and a "substitute" connection with sentiment convergence ( $\Delta p o l)$, respectively. Both results are significant and are consistent with the results from Table 4. A "complementary" connection, therefore, is positively associated with the WOM polarity difference between the connected products, which means a divergence of the overall sentiments between the two products (WOM polarity difference is likely to be bigger if connected via a "complementary" connection). A "substitute" connection, on the other hand, is negatively associated with the sentiment convergence, which means a convergence of the overall sentiments between the two connected products (WOM polarity difference is likely to be smaller if connected via a "substitute" connection).

Because, in NLP, many other textual attributes may associate with sentiment analysis, two additional control variables were included to show the results' consistency. Chevalier and Mayzlin [15] proposed that the length of a review is correlated with the reviewer's level of enthusiasm for the product. The mean review length difference $(\Delta l e n)$ between two products, shown in Model (3B) and (3E) in Table 6, is included to control for this factor. A consistent association with sentiment convergence is found for both connections when review length is included as an additional control variable.

Subjectivity analysis is often a part of sentiment analysis, where researchers classify a text as opinionated (subjective) or not opinionated (objective, factual). The presence of specific terms such as adjectives, adverbs, and some groups of verbs and nouns are taken as indicators of a subjective opinion. The more subjective a text is, the better the NLP algorithm can detect the polarity of a statement [34]. The Pattern library used in the sentiment analysis also uses a built-in model to calculate a review's subjectivity value. A value close to zero indicates an objective review, while a value close to one indicates a highly subjective review. The review subjectivity difference $(\Delta s u b)$ is measured as the absolute value of the difference of the mean subjectivity score between two products. Although model (3C) and (3F) in Table 5 show a consistent finding on sentiment convergence for both connection types when the subjectivity difference is included in the analysis, the significance of model (3C) should be considered with caution due to a $90 \%$ confidence interval for the coefficient of connection.

\subsection{Robustness checks}

A series of robustness checks are conducted to ensure the reliability of the results. The results of robustness checks corresponding to product rating convergence are shown in Table 6 ("substitute" products network) and Table 7 ("complementary" products network). It should be mentioned that in both tables, column A is taken from Table 4 as a baseline comparison for robustness checks benchmarking. In addition, to show that the regression models' contemporaneous specification has not led to any potential bias, an ad hoc solution is used by adding a lagged version of the connection and $\Delta p r$ in separate model specifications. Although the number of observations considerably shrank due to the unbalanced dataset, it sufficed to rule out the potential concerns regarding the contemporaneous regression models. Accordingly, the results for the "substitute" and "complementary" connections remained consistent (see column B and C in Tables 6 and 7).

Moreover, robustness checks for potential collinearity were conducted, even though Table 2 shows that all the correlations were mostly small, which indicated that collinearity was not a major concern. Nevertheless, to assure the results' validity, mean-subtracted centralization and standardization were performed for all independent and control variables in the model. Again, the results show that the findings remained consistent (see column D and E in Tables 6 and 7). Finally, to address a potential heteroscedasticity issue, the model was re-estimated to report robust standard errors, and the results remained consistent (see column $\mathrm{F}$ in Tables 6 and 7).

Some robustness checks are carried away for the sentiment convergence model as well, and the results are shown in Table 8. Several concerns in the robustness of the estimations could already be addressed

Table 5

Results of the "complementary" and "substitute" network connections on sentiment convergence.

\begin{tabular}{|c|c|c|c|c|c|c|}
\hline \multirow[b]{2}{*}{ Variable } & \multicolumn{3}{|c|}{ "complementary" } & \multicolumn{3}{|c|}{ "substitute" } \\
\hline & Model (3A) & Model (3B) & Model (3C) & Model (3D) & Model (3E) & Model (3F) \\
\hline connection & $\begin{array}{l}0.001^{* *} \\
(0.001)\end{array}$ & $\begin{array}{l}0.001 * * \\
(0.001)\end{array}$ & $\begin{array}{l}0.001 * \\
(0.000)\end{array}$ & $\begin{array}{l}-0.003^{* * * *} \\
(0.001)\end{array}$ & $\begin{array}{l}-0.003^{* * *} \\
(0.001)\end{array}$ & $\begin{array}{l}-0.002^{* * * *} \\
(0.001)\end{array}$ \\
\hline$\Delta r v$ & $\begin{array}{l}0.002^{* * *} \\
(0.000)\end{array}$ & $\begin{array}{l}0.002^{* * *} \\
(0.000)\end{array}$ & $\begin{array}{l}0.001^{* * *} \\
(0.000)\end{array}$ & $\begin{array}{l}0.002^{* * * *} \\
(0.000)\end{array}$ & $\begin{array}{l}0.002 * * * \\
(0.000)\end{array}$ & $\begin{array}{l}0.001^{* * *} \\
(0.000)\end{array}$ \\
\hline$\Delta l p$ & $\begin{array}{l}-0.000^{* * *} \\
(0.000)\end{array}$ & $\begin{array}{l}-0.000 * * * \\
(0.000)\end{array}$ & $\begin{array}{l}-0.000^{* * * *} \\
(0.000)\end{array}$ & $\begin{array}{l}-0.000 * * * \\
(0.000)\end{array}$ & $\begin{array}{l}-0.000^{* * * *} \\
(0.000)\end{array}$ & $\begin{array}{l}-0.000^{* * * *} \\
(0.000)\end{array}$ \\
\hline$\Delta i n_{-} d c$ & $\begin{array}{l}0.000 * * * \\
(0.000)\end{array}$ & $\begin{array}{l}0.000^{* * *} \\
(0.000)\end{array}$ & $\begin{array}{l}0.000^{* * *} \\
(0.000)\end{array}$ & $\begin{array}{l}0.000^{* * *} \\
(0.000)\end{array}$ & $\begin{array}{l}0.000^{* * * *} \\
(0.000)\end{array}$ & $\begin{array}{l}0.000 * * * \\
(0.000)\end{array}$ \\
\hline$\Delta o u t \_d c$ & $\begin{array}{l}0.000 * * \\
(0.000)\end{array}$ & $\begin{array}{l}0.000 * \\
(0.000)\end{array}$ & $\begin{array}{l}0.000 * * * \\
(0.000)\end{array}$ & $\begin{array}{l}0.000 * * \\
(0.000)\end{array}$ & $\begin{array}{l}0.000 * * \\
(0.000)\end{array}$ & $\begin{array}{l}0.000^{* * *} \\
(0.000)\end{array}$ \\
\hline assortativity & $\begin{array}{l}0.001 \\
(0.001)\end{array}$ & $\begin{array}{l}0.001 \\
(0.001)\end{array}$ & $\begin{array}{l}0.000 \\
(0.001)\end{array}$ & $\begin{array}{l}0.001 \\
(0.001)\end{array}$ & $\begin{array}{l}0.001 \\
(0.001)\end{array}$ & $\begin{array}{l}0.000 \\
(0.001)\end{array}$ \\
\hline$\Delta l e n$ & & $\begin{array}{l}0.002^{* * *} \\
(0.000)\end{array}$ & & & $\begin{array}{l}0.002^{* * *} \\
(0.000)\end{array}$ & \\
\hline$\Delta s u b$ & & & $\begin{array}{l}0.199^{* * *} \\
(0.001)\end{array}$ & & & $\begin{array}{l}0.199 * * * \\
(0.001)\end{array}$ \\
\hline observations & $2^{\prime} 025 ’ 740$ & $2^{\prime} 025740$ & $2^{\prime} 025 ’ 740$ & $2^{\prime} 025 ’ 740$ & $2^{\prime} 025740$ & $2^{\prime} 025 ’ 740$ \\
\hline network ties & $309^{\prime} 206$ & $309^{\prime} 206$ & $309^{\prime} 206$ & $309^{\prime} 206$ & $309^{\prime} 206$ & $309^{\prime} 206$ \\
\hline days & 31 & 31 & 31 & 31 & 31 & 31 \\
\hline$R^{2}$ & 0.000 & 0.001 & 0.045 & 0.000 & 0.001 & 0.045 \\
\hline
\end{tabular}

Standard errors in parentheses. ${ }^{*} p<0.1,{ }^{* *} p<0.05,{ }^{* * *} p<0.01$ 
Table 6

Robustness checks for the association between network connection "substitute" and rating convergence.

\begin{tabular}{|c|c|c|c|c|c|c|}
\hline Variable & $\begin{array}{l}\text { (A) } \\
\text { Preferred }\end{array}$ & $\begin{array}{l}\text { (B) } \\
\text { Prior connection }\end{array}$ & $\begin{array}{l}\text { (C) } \\
\text { Prior rating }\end{array}$ & $\begin{array}{l}\text { (D) } \\
\text { Centralization }\end{array}$ & $\begin{array}{l}\text { (E) } \\
\text { Standardization }\end{array}$ & $\begin{array}{l}\text { (F) } \\
\text { Heteroscedasticity }\end{array}$ \\
\hline connection & $\begin{array}{l}-0.019 * * * \\
(0.003)\end{array}$ & $\begin{array}{l}-0.015^{* * *} \\
(0.005)\end{array}$ & $\begin{array}{l}-0.007 * * * \\
(0.002)\end{array}$ & $\begin{array}{l}-0.019^{* * *} \\
(0.003)\end{array}$ & $\begin{array}{l}-0.001^{* * *} \\
(0.000)\end{array}$ & $\begin{array}{l}-0.019^{* * *} \\
(0.003)\end{array}$ \\
\hline$\Delta r v$ & $\begin{array}{l}0.068^{* * *} \\
(0.001)\end{array}$ & $\begin{array}{l}0.038^{* * * *} \\
(0.004)\end{array}$ & $\begin{array}{l}0.025^{* * *} \\
(0.000)\end{array}$ & $\begin{array}{l}0.068^{* * * *} \\
(0.001)\end{array}$ & $\begin{array}{l}0.082^{* * *} \\
(0.001)\end{array}$ & $\begin{array}{l}0.068^{* * *} \\
(0.001)\end{array}$ \\
\hline$\Delta l p$ & $\begin{array}{l}-0.001^{* * *} \\
(0.000)\end{array}$ & $\begin{array}{l}0.002 \\
(0.002)\end{array}$ & $\begin{array}{l}-0.000 \\
(0.000)\end{array}$ & $\begin{array}{l}-0.001^{* * *} \\
(0.000)\end{array}$ & $\begin{array}{l}-0.001^{* * *} \\
(0.000)\end{array}$ & $\begin{array}{l}-0.001^{* * *} \\
(0.000)\end{array}$ \\
\hline$\Delta i n_{-} d c$ & $\begin{array}{l}0.000 \\
(0.000)\end{array}$ & $\begin{array}{l}-0.001 \\
(0.001)\end{array}$ & $\begin{array}{l}0.000 \\
(0.000)\end{array}$ & $\begin{array}{l}0.000 \\
(0.000)\end{array}$ & $\begin{array}{l}0.000 \\
(0.000)\end{array}$ & $\begin{array}{l}0.000 \\
(0.000)\end{array}$ \\
\hline$\Delta o u t d c$ & $\begin{array}{l}0.001 * * * \\
(0.000)\end{array}$ & $\begin{array}{l}0.002 \\
(0.002)\end{array}$ & $\begin{array}{l}0.000 * * \\
(0.000)\end{array}$ & $\begin{array}{l}0.001^{* * *} \\
(0.000)\end{array}$ & $\begin{array}{l}0.001^{* * *} \\
(0.000)\end{array}$ & $\begin{array}{l}0.001^{* * *} \\
(0.000)\end{array}$ \\
\hline assortativity & $\begin{array}{l}-0.130^{* * *} \\
(0.004)\end{array}$ & $\begin{array}{l}-0.016 \\
(0.075)\end{array}$ & $\begin{array}{l}-0.001 \\
(0.004)\end{array}$ & $\begin{array}{l}-0.130^{* * *} \\
(0.004)\end{array}$ & $\begin{array}{l}-0.063^{* * *} \\
(0.002)\end{array}$ & $\begin{array}{l}-0.130^{* * *} \\
(0.008)\end{array}$ \\
\hline connection $_{t-1}$ & & $\begin{array}{l}-0.018^{* * *} \\
(0.006)\end{array}$ & & & & \\
\hline$\Delta p r_{t-1}$ & & & $\begin{array}{l}0.258^{* * *} \\
(0.000)\end{array}$ & & & \\
\hline \#observations & $2^{\prime} 025^{\prime} 740$ & $16^{\prime} 519$ & $1^{\prime} 333^{\prime} 272$ & $2^{\prime} 025 ’ 740$ & $2^{\prime} 025 ’ 740$ & $2^{\prime} 025^{\prime} 740$ \\
\hline \#network ties & $309^{\prime} 206$ & $3^{\prime} 380$ & $161^{\prime} 370$ & $309^{\prime} 206$ & $309^{\prime} 206$ & $309^{\prime} 206$ \\
\hline \#days & 31 & 31 & 31 & 31 & 31 & 31 \\
\hline$R^{2}$ & 0.009 & 0.065 & 0.535 & 0.009 & 0.009 & 0.009 \\
\hline
\end{tabular}

Standard errors in parentheses. ${ }^{*} p<0.1,{ }^{* *} p<0.05, * * * p<0.01$.

Table 7

Robustness checks for the association between network connection "complementary" and rating convergence.

\begin{tabular}{|c|c|c|c|c|c|c|}
\hline Variable & $\begin{array}{l}\text { (A) } \\
\text { Preferred }\end{array}$ & $\begin{array}{l}\text { (B) } \\
\text { Prior connection }\end{array}$ & $\begin{array}{l}\text { (C) } \\
\text { Prior rating }\end{array}$ & $\begin{array}{l}\text { (D) } \\
\text { Centralization }\end{array}$ & $\begin{array}{l}\text { (E) } \\
\text { Standardization }\end{array}$ & $\begin{array}{l}\text { (F) } \\
\text { Heteroscedasticity }\end{array}$ \\
\hline connection & $\begin{array}{l}0.006^{* *} \\
(0.003)\end{array}$ & $\begin{array}{l}0.010 * * \\
(0.004)\end{array}$ & $\begin{array}{l}0.005^{* * *} \\
(0.002)\end{array}$ & $\begin{array}{l}0.006 * * \\
(0.003)\end{array}$ & $\begin{array}{l}0.000 * * \\
(0.000)\end{array}$ & $\begin{array}{l}0.006^{* *} \\
(0.003)\end{array}$ \\
\hline$\Delta r v$ & $\begin{array}{l}0.068^{* * * *} \\
(0.001)\end{array}$ & $\begin{array}{l}0.038^{* * *} \\
(0.004)\end{array}$ & $\begin{array}{l}0.025^{* * *} \\
(0.000)\end{array}$ & $\begin{array}{l}0.068^{* * * *} \\
(0.001)\end{array}$ & $\begin{array}{l}0.082^{* * *} \\
(0.001)\end{array}$ & $\begin{array}{l}0.068^{* * *} \\
(0.001)\end{array}$ \\
\hline$\Delta l p$ & $\begin{array}{l}-0.001^{* * *} \\
(0.000)\end{array}$ & $\begin{array}{l}0.002 \\
(0.002)\end{array}$ & $\begin{array}{l}-0.000 \\
(0.000)\end{array}$ & $\begin{array}{l}-0.001^{* * *} \\
(0.000)\end{array}$ & $\begin{array}{l}-0.001^{* * *} \\
(0.000)\end{array}$ & $\begin{array}{l}-0.001^{* * *} \\
(0.000)\end{array}$ \\
\hline$\Delta i n_{-} d c$ & $\begin{array}{l}0.000 \\
(0.000)\end{array}$ & $\begin{array}{l}-0.002 \\
(0.001)\end{array}$ & $\begin{array}{l}0.000 \\
(0.000)\end{array}$ & $\begin{array}{l}0.000 \\
(0.000)\end{array}$ & $\begin{array}{l}0.000 \\
(0.000)\end{array}$ & $\begin{array}{l}0.000 \\
(0.000)\end{array}$ \\
\hline$\Delta o u t_{-} d c$ & $\begin{array}{l}0.001^{* * * *} \\
(0.000)\end{array}$ & $\begin{array}{l}0.001 \\
(0.002)\end{array}$ & $\begin{array}{l}0.000 * \\
(0.000)\end{array}$ & $\begin{array}{l}0.001^{* * *} \\
(0.000)\end{array}$ & $\begin{array}{l}0.001 * * * \\
(0.000)\end{array}$ & $\begin{array}{l}0.001^{* * *} \\
(0.000)\end{array}$ \\
\hline assortativity & $\begin{array}{l}-0.130^{* * * *} \\
(0.004)\end{array}$ & $\begin{array}{l}-0.020 \\
(0.075)\end{array}$ & $\begin{array}{l}-0.001 \\
(0.004)\end{array}$ & $\begin{array}{l}-0.130 * * * \\
(0.004)\end{array}$ & $\begin{array}{l}-0.063^{* * *} \\
(0.002)\end{array}$ & $\begin{array}{l}-0.130^{* * *} \\
(0.008)\end{array}$ \\
\hline connection $_{t-1}$ & & $\begin{array}{l}0.021^{* * *} \\
(0.006)\end{array}$ & & & & \\
\hline$\Delta p r_{t-1}$ & & & $\begin{array}{l}0.258^{* k *} \\
(0.000)\end{array}$ & & & \\
\hline \# observations & $2^{\prime} 025^{\prime} 740$ & $16^{\prime} 519$ & $1^{\prime} 333^{\prime} 272$ & $2^{\prime} 025 ' 740$ & $2^{\prime} 025 ’ 740$ & $2^{\prime} 025 ’ 740$ \\
\hline \# network ties & $309^{\prime} 206$ & $3^{\prime} 380$ & $161^{\prime} 370$ & $309^{\prime} 206$ & $309^{\prime} 206$ & $309^{\prime} 206$ \\
\hline \# days & 31 & 31 & 31 & 31 & 31 & 31 \\
\hline$R^{2}$ & 0.009 & 0.065 & 0.535 & 0.009 & 0.009 & 0.009 \\
\hline
\end{tabular}

Standard errors in parentheses. ${ }^{*} p<0.1,{ }^{* *} p<0.05, * * * p<0.01$.

by including additional control variables in the sentiment model. Nevertheless, the same robustness checks are conducted in order to avoid potential collinearity and heteroscedasticity issues, as in the previous models. Moreover, the results of the re-estimated model of the centralized variables on sentiment convergence show consistent results. Results are confirmed further by including the standardized variables. For both connections, the results remained consistent. Lastly, the reestimated model results with robust standard errors showed both connections "substitute" and "complementary" have a significant association with sentiment convergence. Nevertheless, the significance of the coefficient for connection should be considered with caution due to a $90 \%$ confidence interval when robust standard errors are considered for a complimentary product network.

\section{Discussion and conclusion}

\subsection{Summary of findings}

The findings showed that when the association between the network connection and rating convergence is examined using the aggregated data of all types of product networks, there is no significant relationship between the network connection and rating convergence. Therefore, $\mathrm{H} 1$ is not supported. This is contrary to the findings of Lin and Wang [5] as they showed the existence of a network connection is associated with rating convergence. An explanation for the insignificant result for $\mathrm{H} 1$ and contradiction to the findings of Lin and Wang [5] could be that no distinction was made between the different types of network connections for H1. In the study of Lin and Wang [5], data is only related to one type of product network, while the current study involves multiple types of product networks. Due to the counteracting relationship of the "substitute" and "complementary" connections with product rating convergence, the estimated coefficient was not significant when 
Table 8

Robustness checks for the association between both network connections "substitute" and "complementary" and sentiment convergence.

\begin{tabular}{|c|c|c|c|c|c|c|}
\hline \multirow[t]{2}{*}{ Variable } & $\begin{array}{l}\text { (A) } \\
\text { (complementary) }\end{array}$ & $\begin{array}{l}\text { (B) } \\
\text { (substitute) }\end{array}$ & $\begin{array}{l}\text { (C) } \\
\text { (complementary) }\end{array}$ & $\begin{array}{l}\text { (D) } \\
\text { (substitute) }\end{array}$ & $\begin{array}{l}\text { (E) } \\
\text { (complementary) }\end{array}$ & $\begin{array}{l}\text { (F) } \\
\text { (substitute) }\end{array}$ \\
\hline & \multicolumn{2}{|c|}{ Centralization } & \multicolumn{2}{|c|}{ Standardization } & \multicolumn{2}{|c|}{ Heteroscedasticity } \\
\hline connection & $\begin{array}{l}0.001 * * \\
(0.001)\end{array}$ & $\begin{array}{l}-0.003^{* * *} \\
(0.001)\end{array}$ & $\begin{array}{l}0.000 * * \\
(0.000)\end{array}$ & $\begin{array}{l}-0.000^{* * *} \\
(0.000)\end{array}$ & $\begin{array}{l}0.001 * \\
(0.001)\end{array}$ & $\begin{array}{l}-0.003^{* * *} \\
(0.001)\end{array}$ \\
\hline$\Delta r v$ & $\begin{array}{l}0.002^{* * *} \\
(0.000)\end{array}$ & $\begin{array}{l}0.002^{* * *} \\
(0.000)\end{array}$ & $\begin{array}{l}0.003^{* * *} \\
(0.000)\end{array}$ & $\begin{array}{l}0.003^{* * *} \\
(0.000)\end{array}$ & $\begin{array}{l}0.002^{* * *} \\
(0.000)\end{array}$ & $\begin{array}{l}0.002^{* * *} \\
(0.000)\end{array}$ \\
\hline$\Delta l p$ & $\begin{array}{l}-0.000^{* * *} \\
(0.000)\end{array}$ & $\begin{array}{l}-0.000^{* * *} \\
(0.000)\end{array}$ & $\begin{array}{l}-0.000^{* * *} \\
(0.000)\end{array}$ & $\begin{array}{l}-0.000^{* * *} \\
(0.000)\end{array}$ & $\begin{array}{l}-0.000^{* * *} \\
(0.000)\end{array}$ & $\begin{array}{l}-0.000^{* * *} \\
(0.000)\end{array}$ \\
\hline$\Delta i \underline{-}_{-} d c$ & $\begin{array}{l}0.000 * * * \\
(0.000)\end{array}$ & $\begin{array}{l}0.000 * * * \\
(0.000)\end{array}$ & $\begin{array}{l}0.000 * * * \\
(0.000)\end{array}$ & $\begin{array}{l}0.000 * * * \\
(0.000)\end{array}$ & $\begin{array}{l}0.000 * * * \\
(0.000)\end{array}$ & $\begin{array}{l}0.000 * * * \\
(0.000)\end{array}$ \\
\hline$\Delta o u t d c$ & $\begin{array}{l}0.000^{* * *} \\
(0.000)\end{array}$ & $\begin{array}{l}0.000 * * \\
(0.000)\end{array}$ & $\begin{array}{l}0.000 * * \\
(0.000)\end{array}$ & $\begin{array}{l}0.000 * * \\
(0.000)\end{array}$ & $\begin{array}{l}0.000 * * \\
(0.000)\end{array}$ & $\begin{array}{l}0.000 * * \\
(0.000)\end{array}$ \\
\hline assortativity & $\begin{array}{l}0.001 \\
(0.001)\end{array}$ & $\begin{array}{l}0.001 \\
(0.001)\end{array}$ & $\begin{array}{l}0.001 \\
(0.000)\end{array}$ & $\begin{array}{l}0.001 \\
(0.000)\end{array}$ & $\begin{array}{l}0.001 * \\
(0.000)\end{array}$ & $\begin{array}{l}0.001 * \\
(0.000)\end{array}$ \\
\hline \#observations & $2^{\prime} 025^{\prime} 740$ & $2^{\prime} 025 ' 740$ & $2^{\prime} 025 ’ 740$ & $2^{\prime} 025 ' 740$ & $2^{\prime} 025^{\prime} 740$ & $2^{\prime} 025 ' 740$ \\
\hline \#network ties & $309^{\prime} 206$ & $309^{\prime} 206$ & $309^{\prime} 206$ & $309^{\prime} 206$ & $309^{\prime} 206$ & $309^{\prime} 206$ \\
\hline \#days & 31 & 31 & 31 & 31 & 31 & 31 \\
\hline$R^{2}$ & 0.000 & 0.000 & 0.000 & 0.000 & 0.000 & 0.000 \\
\hline
\end{tabular}

Standard errors in parentheses. ${ }^{*} p<0.1,{ }^{* *} p<0.05$, ${ }^{* * *} p<0.01$.

connections of all types were included in the analysis. This is potentially a good reason for why each type of product network should be examined in isolation. Based on the findings, it is likely that when two products are connected via a "substitute" recommender system, consumers perceive them as equally qualitative. Hence, the "substitute" network connection may increase the rating of the lower-rating product, while it may decrease the rating of the higher-rating product.

Moreover, results show that various types of recommender systems could be associated with product rating convergence in varying ways. Interestingly, the connection via both "complementary" and "substitute" product networks is significantly associated with product rating convergence, but in opposite directions. An explanation for this result could be that the two different types of recommender systems suggested two different kinds of products (i.e., different categories). While a "substitute" recommender mainly recommends products that are very likely to be from the same category, a "complementary" recommendation system mainly recommends products that are from other categories. This study's underlying data shows $89 \%$ of the products in a "substitute" connection are from the same category, while only $7 \%$ of the products in a "complementary" connection are from the same category. While a consumer may perceive two products that are connected via a "substitute" recommendation as qualitatively equal, he will see two products from two different categories as two distinct products, which do not necessarily, share the same perceived status. Apparently, such a "complementary" connection between the products reinforces the perceived quality a customer has of the two products, which may cause him to leave stronger opposing ratings for the products. A "complementary" network connection between two products could decrease the lower product rating but increase the higher product rating, which leads to divergence and causes them to be more apart from one another.

The results in the sentiment model showed a significant association between network connections and sentiment convergence. Both types of network connections (i.e., "complementary" and "substitute") in the sentiment model show similar results as in the products' rating model. Literature suggests being exposed to different information sources due to the difference in the type of product network is associated with customers' purchase decisions and online behavior [11]. These findings provide a further understanding of product networks' role in the way online reviews are generated from the perspective of sentiments embedded in customers' reviews. In other words, customers are likely to express their emotions in different ways depending on being exposed to recommended products from different types of product networks.

\subsection{Theoretical contributions}

The contribution of this research is threefold. First, it extends the existing knowledge by differentiating between the types of network connection between two products. Findings show that a network connection between two products via a "substitute" recommender is associated with the convergence of the two products' ratings. In contrast, a connection via a "complementary" recommender is associated with product ratings' divergence. Therefore, the type of product network matters! Unlike prior research studies $[5,10]$ that had exclusively considered only one type of product network when there were more of them, this paper suggests a critical point in that regard. This paper suggests that it is better to include different types of product networks and examine their association with customer ratings and sentiments in isolation when there is more than one type of recommenders on an e-commerce platform.

Second, this study incorporates not only the numerical ratings but also textual characteristics of reviews, which allows for the examination of sentiments that are expressed by customers. Findings show that a connection of "substitute" ("complementary") type is associated with the convergence (divergence) of the two products' overall review sentiments. This is very likely to be the first study to show such a relationship and, therefore, adds to the recent evolving conversation on the different outcomes of varying product networks.

Last but not least, since the literature in the underlying context has mostly relied on data from e-commerce stores such as Amazon.com or Tmall.com, this study adds to the conversation by presenting insights drawn from data of a different e-commerce store based in Switzerland. Besides contributing to the generalizability of the findings in the underlying literature, this study emphasizes on the different characteristics of e-commerce stores regarding their recommendation systems. As discussed earlier in the paper, it is important to differentiate between online platforms since each of them may have varying characteristics (e.g., website design), context, and target audience [4]. The results did not support the first hypothesis in this study, unlike the findings of Lin and Wang [5]. It could potentially be due to those differences. Therefore, when it comes to the generalizability of the findings of studies in the context of e-commerce, it is crucial to consider such unique contextual aspects of e-commerce platforms.

\subsection{Practical implications}

This study has important implications for e-commerce platforms to improve the use of recommendation systems and, consequently, their 
business. Mainly, the idea of managing WOM in e-commerce platforms is a relatively new topic that has a high potential for practitioners in ecommerce to monitor and improve WOM in their platforms strategically. Accordingly, this study provides important insights for e-commerce platforms by pointing out that the type of connection between a pair of products through recommendation systems can be associated with WOM properties, such as product ratings and customers' sentiment. Therefore, by employing the findings of this study in the design and development of recommendation systems, e-commerce platforms can improve their recommendation systems' efficiency in a direction that also improves WOM on their platform.

Also, some e-commerce platforms use multiple recommenders in their website interface. A critical question is what kind of recommenders should be chosen and placed on the website interface to maximize the benefits of the e-commerce platform as well as providing utilities for customers. For instance, the underlying e-commerce platform in this study uses several types of recommenders, while at the time of this research, only two recommenders were placed on a focal product's webpage. Therefore, selecting the right recommender on each focal product's web page could be a crucial decision for platform managers. In such a circumstance, our findings can help platform managers in making a better decision, which is driven by data. However, to ensure that these findings are relevant to their business context, they could also replicate the underlying analytical procedure in this study.

Second, this study presents valuable insights for those e-commerce platforms that recommend sponsored products to their customers. In other words, there are platforms such as Amazon that allow advertisers to place their products on other products' webpages for a cost [10]. In such a situation, both producers and e-commerce platforms can strategically manage the WOM in regard to those sponsored recommendations by paying attention to how and to what product they should link the sponsored product. A proper decision on the placement of the sponsored product in the right product network and establishing links on specific products can potentially improve the rating and the overall customer sentiment of the sponsored product. Accordingly, both e-commerce platforms and producers can take a reasonable step toward maximizing their benefits.

\subsection{Limitations and future directions}

Like any other research, the results of this study should be treated with caution due to limitations. Both the data collection process and the applied empirical analysis must be considered when looking at the results. As mentioned earlier, the type of network connection and its underlying mechanism is often difficult to observe and can only be inferred indirectly. Additionally, each recommender system differs from one online shop to another online shop. Therefore, replication of this study on other online shops could help with the generalization of the findings. The observed association between "complementary" connections and WOM convergence could, therefore, be a peculiarity for the Swiss ecommerce store in this study due to its unique recommendation system.

Furthermore, a sampling bias during the data collection process could have affected the outcome of the analysis. By only gathering the top 100 products for one month, no isolated product network could be examined, and only a fracture of the existing network connections in the e-commerce store could be observed. Therefore, a more sophisticated and complete sample of product networks could add to our understanding of this study's reported findings. Moreover, as mentioned earlier, due to an interface update on the underlying e-commerce website, the website stopped recommending substitute products the way it used to in the middle of the data collection process. The likelihood of recommending complementary products was slightly increased. Accordingly, the observations for substitute products are available for a shorter period in the data, which is a limitation regarding to the analysis. Nevertheless, the findings are reported by controlling for the timeinvariant heterogeneity to ensure such limitation has not biased the results much. Future research could consider a more robust data collection procedure, or, most preferably, experimental design to conduct a more robust causal inference regarding this phenomenon.

Regarding the sentiment analysis, one could argue that sentiment polarity is a one-dimensional metric, which would only partially reflect the embedded information in the written reviews and therefore show the same shortcomings of a regular numerical product rating. Nevertheless, the product polarity score remains an ideal summary metric for the expressed sentiments toward a product, as it not only shows a dichotomous sentiment (positive review, negative review) but a gradation of positive and negative sentiments. Therefore, the WOM polarity can be viewed as a broken-down product rating, which keeps only the overall sentiments and ignores the majority of additional factors that make up a WOM rating. Although this would suffice to address the research objective, a more in-depth text analysis could have brought forth more insights, which could be important in answering the second research question in more detail.

Moreover, due to the unavailability of the sales/purchase data of the underlying e-commerce website, this empirical study is limited in providing a broader understanding of the direct or mediated relationship between the product network type and sales performance of the ecommerce website. Although this was not the aim of this study, it could potentially be an interesting question to investigate, and there is a potential for further studies. In addition, in some e-commerce platforms such as the underlying e-commerce website in this study, every registered customer can submit a review about a product even if she has not actually purchased the product. Thus, it was not possible to determine the extent to which the ratings and reviews in this study are generated based on authentic purchasing and experiencing a product. Even though the extent of the reviews' subjectivity was included in the analysis as a control variable, the issue of authentic vs. deceptive reviews and ratings is important enough to be explored deeper by future research. In particular circumstances or events, such as the COVID-19 pandemic, customers may act or behave differently when shopping online. Thus, it would be interesting to see how spillover of WOM occurs at the time of special events like the COVID-19 pandemic.

\section{Conclusion}

The aim of this paper is to examine whether and how various product networks are associated with the convergence/divergence of online reviews (i.e., ratings and review sentiments). Findings show that the network connection between two products leads to the convergence of the two products' ratings, but only if the two products are connected via a "substitute" recommender system. On the other hand, a "complementary" recommender connection leads to the divergence of the two products' ratings. Additionally, both of these network connections showed to have the same outcomes for sentiment convergence. This is an indicator that different kinds of product networks are associated with the way online reviews may converge or diverge. This paper contributes to the emerging literature on product networks and opinion convergence by providing important insights. Moreover, it provides valuable insights for practice in terms of improving the design of e-commerce platforms, choosing effective recommendations systems, and improving the effectiveness of recommendation systems.

\section{References}

[1] J. Clement, Retail e-commerce Sales Worldwide From 2014 to 2023 (in billion U.S. dollars). https://www.statista.com/statistics/379046/worldwide-retail-e-commer ce-sales/, 2020 (accessed September 5, 2020).

[2] ACI Worldwide, Global eCommerce Retail Sales Up 209 Percent in April, ACI Worldwide Research Reveals, 2020. https://www.aciworldwide.com/news-and-e vents/press-releases/2020/may/global-ecommerce-retail-sales-up-209-percent-i n-april-aci-worldwide-research-reveals (accessed September 6, 2020).

[3] C. Dellarocas, The digitization of word of mouth: promise and challenges of online feedback mechanisms, Manag. Sci. 49 (2003) 1407-1424. 
[4] J. Huang, W.F. Boh, K.H. Goh, Opinion convergence versus polarization: examining opinion distributions in online word-of-mouth, J. Assoc. Inf. Sci. Technol. 70 (2019) 1183-1193.

[5] Z. Lin, Q. Wang, E-commerce product networks, word-of-mouth convergence, and product sales, J. Assoc. Inf. Syst. 19 (2018) 23-39.

[6] S. Zhou, B. Guo, The order effect on online review helpfulness: a social influence perspective, Decis. Support. Syst. 93 (2017) 77-87.

[7] Z. Zhang, X. Li, Y. Chen, Deciphering word-of-mouth in social media: text-based metrics of consumer reviews, ACM Trans. Manage. Inform. Syst. (TMIS). 3 (2012) $1-23$.

[8] G. Oestreicher-Singer, A. Sundararajan, The visible hand? Demand effects of recommendation networks in electronic markets, Manag. Sci. 58 (2012) 1963-1981.

[9] B. Smith, G. Linden, Two decades of recommender systems at amazon.com, IEEE Internet Comput. 21 (2017) 12-18.

[10] A. Kumar, K. Hosanagar, Measuring the value of recommendation links on product demand, Inf. Syst. Res. 30 (2019) 819-838.

[11] Z. Lin, K.Y. Goh, C.-S. Heng, The demand effects of product recommendation networks: an empirical analysis of network diversity and stability, MIS Q. 41 (2017) 397-426.

[12] H.J. Huang, J. Yang, B. Zheng, Demand effects of product similarity network in ecommerce platform, Electron. Commer. Res. (2019) 1-31.

[13] E. Carmi, G. Oestreicher-Singer, U. Stettner, A. Sundararajan, Is oprah contagious? The Stwork, MIS Q. 41 (2017) 207-221.

[14] G. Oestreicher-Singer, A. Sundararajan, Recommendation networks and the long tail of electronic commerce, MIS Q. 36 (2012) 65-83.

[15] J.A. Chevalier, D. Mayzlin, The effect of word of mouth on sales: online book reviews, J. Mark. Res. 43 (2006) 345-354.

[16] A. Ghose, P.G. Ipeirotis, Estimating the helpfulness and economic impact of product reviews: mining text and reviewer characteristics, IEEE Trans. Knowl. Data Eng. 23 (2010) 1498-1512.

[17] X. Li, C. Wu, F. Mai, The effect of online reviews on product sales: a joint sentiment-topic analysis, Inf. Manag. 56 (2019) 172-184.

[18] Z. Lin, An empirical investigation of user and system recommendations in ecommerce, Decis. Support. Syst. 68 (2014) 111-124.

[19] J. Leskovec, A. Rajaraman, J.D. Ullman, Mining of Massive Datasets, 2nd ed., Cambridge university press, Croydon, 2014.

[20] D.H. Park, H.K. Kim, I.Y. Choi, J.K. Kim, A literature review and classification of recommender systems research, Expert Syst. Appl. 39 (2012) 10059-10072.

[21] H.K. Kim, J.K. Kim, Q.Y. Chen, A product network analysis for extending the market basket analysis, Expert Syst. Appl. 39 (2012) 7403-7410.

[22] C. Forman, A. Ghose, B. Wiesenfeld, Examining the relationship between reviews and sales: the role of reviewer identity disclosure in electronic markets, Inf. Syst. Res. 19 (2008) 291-313.

[23] B. Pathak, R. Garfinkel, R.D. Gopal, R. Venkatesan, F. Yin, Empirical analysis of the impact of recommender systems on sales, J. Manag. Inf. Syst. 27 (2010) 159-188.
[24] A. Edmunds, A. Morris, The problem of information overload in business organisations: a review of the literature, Int. J. Inf. Manag. 20 (2000) 17-28.

[25] A. Benlian, R. Titah, T. Hess, Differential effects of provider recommendations and consumer reviews in e-commerce transactions: an experimental study, J. Manag. Inf. Syst. 29 (2012) 237-272.

[26] Z. Lin, C.-S. Heng, The paradoxes of word of mouth in electronic commerce, J. Manag. Inf. Syst. 32 (2015) 246-284.

[27] R. Ahluwalia, H.R. Unnava, R.E. Burnkrant, The moderating role of commitment on the spillover effect of marketing communications, J. Mark. Res. 38 (2001) $458-470$.

[28] N. Hu, N.S. Koh, S.K. Reddy, Ratings lead you to the product, reviews help you clinch it? The mediating role of online review sentiments on product sales, Decis. Support. Syst. 57 (2014) 42-53.

[29] B. Pathak, R. Garfinkel, R. Gopal, R. Venkatesan, F. Yin, Empirical analysis of the impact of recommender systems on sales, J. Manag. Inf. Syst. 27 (2010) 159-188, https://doi.org/10.2753/MIS0742-1222270205.

[30] Google Cloud Translation API v3, Cloud Translation API Documentation. https://cloud.google.com/translate/docs/, 2020 (accessed March 27, 2020).

[31] TextBlob API v0.15.2, TextBlob API Documentation. https://textblob.readthedocs. io, 2020 (accessed March 27, 2020).

[32] T. De Smedt, W. Daelemans, Pattern for python, J. Mach. Learn. Res. 13 (2012) 2063-2067.

[33] N. Li, D.D. Wu, Using text mining and sentiment analysis for online forums hotspot detection and forecast, Decis. Support. Syst. 48 (2010) 354-368, https://doi.org/ 10.1016/j.dss.2009.09.003.

[34] B. Pang, L. Lee, A sentimental education: Sentiment analysis using subjectivity summarization based on minimum cuts, in: Proceedings of the 42nd Annual Meeting on Association for Computational Linguistics, Association for Computational Linguistics, 2004, p. 271.

David Robert Stöckli is a Digital Analyst holding master's and bachelor's degrees in business administration from the University of Bern in Switzerland. His research interests include digital analytics, conversion rate optimization, recommender systems, online user behavior, user engagement, and data science applications in online marketing.

Hamid Khobzi is an Assistant Professor of Information Systems at the University of Bern in Switzerland. He holds a PhD degree in Information Systems from City University of Hong Kong. He has also undertaken his research at the Desautels Faculty of Management, McGill University as a visiting scholar. His research interests include data science applications in business, social media, user engagement, online social interactions, and online social movements. His research has appeared in peer-reviewed journals and conference proceedings such as Internet Research, Computers in Human Behavior, the Hawaii International Conference on System Sciences, and the Americas Conference on Information Systems. 